\title{
PERLINDUNGAN HUKUM DARI PAPARAN ASAP ROKOK DI KOTA BLITAR
}

\section{Weppy Susetiyo, M. Taufan Perdana, Anik Iftitah; Fakultas Hukum Universitas Islam Balitar,} Jl. Mojopahit No. 12A, Blitar, Jawa Timur; E-mail: weppy_s@yahoo.co.id

\begin{abstract}
Abstrak
Melalui penelitian yuridis normatif guna meneliti perwujudan perlindungan hukum pemerintah di tingkat daerah di Kota Blitar secara preventif dan represif terhadap aktifitas merokok di Kota Blitar, diketahui bahwa regulasi Perda KTR Kota Blitar yang mengandung sanksi administratif bagi pihak terkait yang tidak melaksanakan kewajiban dan sanksi pidana bagi pelaku tindak pidana pelanggaran, memperbolehkan smoking area di tempat kerja, dan melarang smoking area di kawasan fasilitas pelayanan kesehatan, tempat proses belajar mengajar, tempat anak bermain, tempat ibadah dan angkutan umum.
\end{abstract}

Kata Kunci: Perlindungan Hukum, Asap Rokok, Perda KTR Kota Blitar.

\section{Abstract}

Through normative juridical research to examine the realization of government legal protection at the regional level in Blitar City in a preventive and repressive manner against smoking activities in Blitar City, it is known that the regulation of the Blitar City No Smoking Area Regional Regulation contains administrative sanctions for related parties who do not carry out criminal obligations and sanctions. For perpetrators of criminal offenses, allowing smoking areas in the workplace, and prohibiting smoking areas in health service facilities, teaching and learning places, places for children to play, places of worship and public transportation.

Keywords: Legal Protection, Cigarette Smoke, Regional Regulations in Blitar City No Smoking Areas.

\section{PENDAHULUAN}

\section{Latar Belakang}

Setiap orang berhak mendapatkan perlindungan hukum dari paparan asap rokok orang lain. Undang-Undang Dasar Negara Republik Indonesia 1945 (UUD NRI1945) Pasal $28 \mathrm{H}$ ayat (1) menyatakan bahwa setiap orang memiliki hak azasi untuk hidup sehat dan lingkungan sehat. Begitu pula dalam Deklarasi Universal tentang hak asasi manusia, menyebutkan bahwa : "tiap orang mempunyai hak untuk hidup pada standar yang layak untuk kesehatan dan kesejateraan mereka, termasuk hak untuk mendapat makanan, perumahan, dan pelayanan kesehatan". ${ }^{1}$ Kepastian perlindungan hukum bagi bukan perokok terhadap paparan asap rokok orang lain tereprentasi melalui peraturan perundang-undangan. ${ }^{2}$ Paparan asap rokok orang lain harus dikendalikan, karena itulah Pemerintah telah mengeluarkan peraturan perundang-undangan guna menjamin kepastian perlindungan hukum bagi bukan perokok terhadap paparan asap rokok orang lain, seperti Undang-Undang Republik Indonesia Nomor 36 Tahun 2009 tentang Kesehatan (UU Kesehatan). Berdasarkan ketentuan di atas maka hidup sehat merupakan hak asasi manusia setiap orang.

\footnotetext{
${ }^{1}$ Everyone has the right to a standard of living adequate for the health and well-being of himself and of his family, including food, clothing, lifehousing and medical care.

${ }^{2}$ Asap rokok orang lain merupakan gabungan asap dari ujung rokok yang menyala (yang kadar racunnya 3 kali lipat asap utama) dan seringkali ditambah dengan asap yang dihembuskan keluar oleh perokok.
} 
Pada tahun 2001, angka kejadian akibat penyakit yang berkaitan dengan kebiasaan merokok yang dilaporkan di Indonesia adalah 427,948 kematian $(22,6 \%)$, penduduk berumur di atas 10 tahun yang merokok sebesar 29,2\% dan meningkat sebesar 34,7\% pada tahun 2010 untuk kelompok umur di atas 15 tahun. Tahun 2007 terjadi peningkatan prevalensi perokok pada kelompok umur 15-24 tahun, dari 17,3\% menjadi 18,6\% atau naik hampir $10 \%$ dalam kurun waktu tiga tahun. Peningkatan juga terjadi pada kelompok umur produktif, yaitu 25-34 tahun dari 29,0\% pada tahun 2007 menjadi 31,1\% pada tahun 2010.3 Penggunaan tembakau pada usia 15 tahun dan 15 tahun ke atas secara dihisap dan dikunyah meningkat dari $34,2 \%$ pada tahun 2007 , menjadi $34,7 \%$ pada tahun 2010 , dan meningkat lagi pada tahun 2013 menjadi 36,3\%.4

Asap rokok mengandung 4000 senyawa kimia, 69 diantaranya adalah penyebab kanker (karsonigenik). Dampak kesehatan akibat paparan asap rokok orang lain antara lain menimbulkan berbagai penyakit jantung dan paru ${ }^{5}$, menimbulkan persalinan bermasalah, bayi berat badan lahir rendah, lahir mati dan bayi lahir cacat, ${ }^{6}$ pada anakanak menimbulkan menimbulkan paru yang lambat, lebih mudah terkena bronkitis, infeksi saluran pernafasan dan telinga tengah, serta asma7. Merokok dapat meningkatkan jumlah sel yang mengalami peradangan dan kerusakan alveoli pada jaringan paru-paru. Merokok dapat menyebabkan peradangan ringan hingga terjadinya penyempitan pada saluran pernapasan kecil sebagai akibat dari meningkatnya jumlah sel dan penumpukan lendir. Dengan adanya perubahan struktur paru-paru, fungsi paru-paru pada perokok dapat berubah. Berubahnya struktur paru-paru merupakan penyebab PPOK (Penyakit Obstruksi Paru-paru Kronis), seperti asma, bronkitis kronis dan pembengkakan (emfisema) pada paru-paru. Bahaya lain dari merokok adalah dapat menyebabkan penyakit kanker paru-paru. Kandungan partikel karsinogenik yang terdapat dalam rokok dapat meningkatkan resiko terkena penyakit kanker paru-paru. Perokok lebih berisiko terkena penyakit kanker paru-paru 10 hingga 30 kali lipat. ${ }^{8}$

Implikasi bahaya rokok yang tidak hanya menyerang keberlangsungan kesehatan secara individual namun juga secara sosial seperti yang telah dipaparkan di atas, kontras dengan kondisi Indonesia yang berada pada urutan ketiga sebagai negara dengan

\footnotetext{
${ }^{3}$ Nizwardi Azkha, "Studi Efektivitas Penerapan Kebijakan Perda Kota Tentang Kawasan Tanpa Rokok (KTR) dalam Upaya Menurunkan Perokok Aktif di Sumatera Barat Tahun 2013", Jurnal Kebijakan Kesehatan Indonesia, Vol. 02, No. 4 Desember 2013, h. 172.

${ }^{4}$ Ekowati Rahajeng, Pengaruh Penerapan Kawasan Tanpa Rokok Terhadap Penurunan Proporsi Perokok di Provinsi DKI Jakarta, Daerah Istimewa Yogyakarta dan Bali, Jurnal Ekologi Kesehatan Vol. 14 No 3, September 2015, h. 239.

${ }^{5}$ International Agency Research on Cancer (IARC) Monograph Evaluation of Carcinogenic Risks to Humans, Tobacco Smoke and Involuntary Smoking July 2002 , http://monograph.iarc.fr/htdocs/indexe s/vol83index.html

${ }^{6}$ Chan-Yeung and Ward. Respiratory health effects of exposure to environtmental tobacco smoke.

${ }^{7}$ http://www.cdc.gov/tobacco/global/gyts/GYTS_factsheets.htm

${ }^{8}$ Kwe Fei Lie Shirley, Endang Wahyati Y. dan Tammy Juwono Siarif. Kebijakan tentang Pedoman Kawasan Tanpa Rokok Dikaitkan dengan Asas Manfaat. SOEPRA Jurnal Hukum Kesehatan, Vol. 2 No. 1 Th. 2016, h. 105.
} 
konsumsi rokok terbesar di dunia setelah China dan India. ${ }^{9}$ Dan menjadi negara dengan jumlah perokok terbanyak di ASEAN yaitu sejumlah 65, 19 juta orang atau setara dengan 34\% penduduk Indonesia tahun 2016. ${ }^{10}$ Pada tahun 2007 sebanyak 14,6 juta orang dewasa terpapar asap tembakau di tempat kerja, di rumah sebanyak 133, 3 juta orang, 85,4\% yang mengunjungi restoran, dan sebanyak $70 \%$ pada transportasi publik. ${ }^{11}$

Kekontrasan fakta tersebut di atas, juga terefleksi di tingkat daerah seperti yang terjadi di Kota Blitar, Jawa Timur. Indikasi kekontrasan tersebut, antara lain dengan adanya jumlah unit usaha industri tembakau di Kota Blitar yang masuk kategori klasifikasi unit usaha terbanyak di wilayah ini. ${ }^{12}$ Padahal aktifitas terhadap hasil industri rokok (merokok) juga memberikan beban kesehatan dan ekonomi kepada orang lain. ${ }^{13}$ Lingkungan bebas asap rokok $100 \%$ adalah satu-satunya cara efektif untuk mengurangi paparan asap rokok orang lain di dalam ruangan. Menyatukan area merokok dan tidak merokok dalam satu ruangan yang sama, walaupun dengan ventilasi udara, tidak aman dan tidak dianjurkan.

\section{Rumusan Masalah}

Negara dalam hal ini Pemerintah Kota Blitar, harus hadir guna melindungi warganya dari implikasi negatif atas berbagai produk tembakau, terutama rokok. Hak bukan perokok untuk menghirup udara bersih di tempat umum, harus mendapat jaminan dan kepastian dari negara. Mempertimbangkan hal tersebut di atas, menjadi urgen untuk meneliti bagaimana perwujudan perlindungan hukum dari paparan asap rokok di Kota Blitar.

\section{METODE PENELITIAN}

Metode penelitian yang digunakan dalam menjawab permasalahan dalam penelitian ini adalah metode penelitian yuridis normative. Penelitian hukum normatif mencitrakan hukum sebagai disiplin preskriptif yang melihat hukum dari sudut pandang norma-normanya. ${ }^{14}$ Dalam konteks penelitian ini, pokok kajiannya adalah Peraturan Daerah Kota Blitar Nomor 1 Tahun 2019 tentang Kawasan tanpa Rokok (Perda KTR Kota Blitar).

Sesuai dengan tipe penelitian yuridis normatif maka data yang dikumpulkan adalah data sekunder. Data sekunder di bidang hukum yang digunakan dalam penelitian ini mencakup tiga bagian yaitu:

a. Bahan Hukum Primer yaitu bahan-bahan hukum yang mengikat, terdiri dari:

1) Undang-Undang Dasar Negara Republik Indonesia 1945 (UUD NRI 1945)

2) Undang-Undang Republik Indonesia Nomor 36 Tahun 2009 tentang Kesehatan (UU Kesehatan)

\footnotetext{
${ }^{9}$ Intan Suryantisa, 2018, Situasi Umum Konsumsi Tembakau di Indonesia, Jakarta: Kementerian Kesehatan RI, h. 1.

10 https://databoks.katadata.co.id/datapublish/2019/05/31/indonesia-negara-dengan-jumlahperokok-terbanyak-di-asean, diakses pada Juli 2020.

11 Op. Cit. Intan Suryantisa, 2018, h. 6.

${ }^{12}$ Baca Kota Blitar dalam Angka 2020, Blitar: BPS Kota Blitar, h. 258.

13 Ibid, h. 7-10.

${ }^{14}$ Depri Liber Sonata, Op. Cit. h.25.
} 
3) Peraturan Daerah Kota Blitar Nomor 1 Tahun 2019 tentang Kawasan tanpa Rokok (Perda KTR Kota Blitar)

b. Bahan Hukum Sekunder adalah bahan hukum yang terdiri atas buku-buku teks yang ditulis para ahli hukum yang berpengaruh, jurnal-jurnal hukum, pendapat para sarjana, kasus-kasus hukum, yurispudensi, dan hasil-hasil simposium mutakhir yang berkaitan dengan penelitian. ${ }^{15}$

c. Bahan hukum tersier adalah bahan hukum yang memberikan petunjuk atau penjelasan terhadap bahan hukum primer dan bahan hukum sekunder seperti kamu hukum, ensiklopedia, dan lain-lain.16

Teknik pengumpulan data dalam penelitian ini, dilakukan dengan desk study. Bahan hukum yang telah terkumpul diklasifikasikan, dianalisis dengan cara menggali asas, nilai serta norma pokok yang terkandung di dalamnya. Selanjutnya dilakukan cross-check dengan peraturan perundang-undangan yang lain untuk menemukan taraf sinkronisasi/harmonisasinya, adakah inkonsistensi di antara peraturan perundangundangan tersebut. Analisis data tersebut dilakukan secara kualitatif melalui penelaahan logika berpikir secara deduktif. ${ }^{17}$ Hasil penelitian disajikan dalam bentuk uraian-uraian yang tersusun secara sistematis.

\section{PEMBAHASAN}

Alenia 4 Pembukaan Undang-Undang Dasar Negara Republik Indonesia Tahun 1945 (Pembukaan UUD NRI 1945) menyatakan bahwa negara yang berkewajiban memberikan perlindungan terhadap warga negara Indonesia. Pemerintah merupakan wakil dari negara dalam menjalankan fungsi perlindungan hukum berkaitan dengan jaminan hak azasi dari Konstitusi Negara Indonesia untuk hidup sehat dan lingkungan sehat, baik berupa perlindungan hukum secara preventif maupun secara represif. ${ }^{18}$ Pemerintah Kota Blitar, sebagai representasi pemerintah di tingkat daerah, memiliki tanggung jawab untuk memenuhi hak masyarakat agar dapat hidup sehat.

Kebijakan atas dasar kesukarelaan saja, tidak dapat diterima. Sehingga terhadap paparan asap rokok sebagai salah satu faktor penentu kualitas warga dan lingkungan yang sehat, Pemerintah Kota Blitar menetapkan Peraturan Daerah Kota Blitar Nomor 1 Tahun 2019 tentang Kawasan tanpa Rokok (Perda KTR Kota Blitar) sebagai wujud perlindungan hukum terhadap aktifitas merokok di wilayah Kota Blitar, untuk melindungi kesehatan orang bukan perokok di wilayah Kota Blitar terhadap efek

\footnotetext{
15 Johnny Ibrahim. (2011). Teori dan Metode Penelitian Hukum Normatif. Cet. 4, Malang: Bayumedia Publishing, 2011, h. 296.

16 Ibid.

17 Baca Prof. Dr. Suteki, S.H.,M.Hum., dan Galang Taufani, S.H.,M.H (2018). Metodologi Penelitian Hukum (Filsafat, Teori dan Praktik). Depok: Rajawali Pers. h. 267.

18 Perlindungan hukum preventif yaitu perlindungan hukum yang bertujuan untuk mencegah terjadinya sengketa, yang mengarahkan tindakan pemerintah bersikap hati-hati dalam pengambilan keputusan berdasarkan diskresi, sedangkan perlindungan hukum represif yaitu perlindungan hukum yang bertujuan bertujuan untuk menyelesaikan sengketa (Phillipus M. Hadjon, Perlindungan Hukum bagi Rakyat Indonesia, Surabaya: PT. Bina Ilmu, 1987, h. 2.)
} 
paparan asap rokok orang lain yang membahayakan. Perda KTR Kota Blitar ini, juga lahir dari perintah yuridis Pasal 115 ayat 2 Undang-Undang Republik Indonesia Nomor 36 Tahun 2009 tentang Kesehatan (UU Kesehatan). ${ }^{19}$

Dengan ditetapkannya regulasi berupa Perda KTR di Kota Blitar ini, dapat dipahami bahwa Pemerintah Kota Blitar, mempunyai niatan nyata untuk melakukan pengendalian terhadap konsumsi rokok/aktifitas merokok di Kota Blitar, kendati di daerah ini terdapat industri tembakau dengan prosentasi tinggi dari total jumlah unit usaha di Kota Blitar. Dengan penerapan Perda KTR di Kota Blitar ini berarti Kota Blitar menambah jumlah kabupaten/kota di Indonesia yang sudah menerapkan perda terkait KTR, dimana pada tahun 2012, dari 497 kabupaten/kota yang ada di Indonesia, hanya sebagian kecil yang sudah menerapkan perda terkait KTR, yaitu antara lain DKI Jakarta, Bogor, Bandung, Cirebon, Palembang, Surabaya, D.I.Yogyakarta, Bangli dan Padang Panjang. Sementara pada tingkat provinsi, DKI Jakarta, Sumatera Selatan, Sumatera Barat, Bali, Kalimantan Barat, Jawa Barat, Jawa Tengah, Jawa Timur, D.I.Yogyakarta, Sulawesi Selatan, NTB dan NTT.20

Perda KTR Kota Blitar tidak berbicara masalah apakah orang boleh merokok, tetapi mengenai tempat dimana orang dapat merokok. Kawasan Tanpa Rokok (KTR) merupakan ruangan atau area yang dinyatakan dilarang untuk kegiatan merokok atau kegiatan memproduksi, menjual, mengiklankan, dan/atau mempromosikan produk tembakau seperti ruangan atau area: (1) fasilitas pelayanan kesehatan, (2) tempat proses belajar mengajar, (3) tempat anak bermain, (4) tempat ibadah, (5) angkutan umum, (6) tempat kerja; dan (7) tempat umum dan tempat lain yang ditetapkan. Perlu kita pahami bahwa produk tembakau yang dimaksud dalam Perda KTR adalah semua produk dari daun tembakau yang dikonsumsi dengan cara dibakar, dihisap, dan dihirup. ${ }^{21}$ Lebih detailnya, KTR di wilayah Kota Blitar meliputi 1. rumah sakit, 2. puskesmas, 3. tempat praktik dokter, 4. klinik, 5. tempat bersalin dan/atau tempat praktik bidan, 6. apotek, 7. Pendidikan dasar dan pendidikan menengah, 8. perguruan tinggi, 9. balai pendidikan dan pelatihan, 10. perpustakaan, 11. ruang praktik/laboratorium, 12. museum, 13. lembaga pendidikan keagamaan atau satuan pendidikan kegamaan, 14. pendidikan anak usia dini, 15. tempat penitipan anak, 16. arena bermain anak-anak, 17. taman bermain, 18. masjid, 19. mushola, 20. gereja, 21. kapel/gereja kecil, 22. pura, 23. wihara, 24. klenteng, 25. bus umum, 26. angkutan kota, 27. taksi, 28. angkutan berbasis media elektronik, 29. perkantoran pemerintah, 30. perkantoran swasta, 30. industri/pabrik, 31. prasarana olahraga, 32. toko swalayan, 33. pasar rakyat, 34. tempat wisata, 35. tempat hiburan, 36.

\footnotetext{
${ }^{19}$ Undang-Undang Republik Indonesia Nomor 36 Tahun 2009 tentang Kesehatan Pasal 115 ayat 2: "Pemerintah daerah wajib menetapkan Kawasan tanpa rokok di wilayahnya".

${ }^{20}$ Juanita, Kebijakan Kawasan Tanpa Rokok: Peluang dan Hambatan, Jurnal Kebijakan Kesehatan Indonesia, Vol. 01, No. 2 Juni 2012, h.116.

${ }^{21}$ Angka 14 Pasal 1 Peraturan Daerah Kota Blitar Nomor 1 Tahun 2019 tentang Kawasan Tanpa Rokok Produk tembakau adalah suatu produk yang secara keseluruhan atau sebagian terbuat dari daun tembakau sebagai bahan bakunya yang diolah untuk digunakan dengan cara dibakar, dihisap, dan dihirup.
} 
hotel, 37. restoran, 38. tempat rekreasi, 39. halte, 40. terminal, dan 41. KTR melalui Keputusan Walikota.

Tempat khusus untuk merokok atau smoking area dapat disediakan di wilayah KTR tempat kerja. Namun smoking area terlarang/tidak dapat disediakan di wilayah KTR pada fasilitas pelayanan kesehatan, tempat proses belajar mengajar, tempat anak bermain, tempat ibadah dang angkutan umum.

Perda KTR Kota Blitar merupakan representasi dari perlindungan hukum pemerintah terhadap warganya secara preventif maupun represif. Kerepresifan perlindungan hukum pemerintah terhadap warga Kota Blitar melalui Perda KTR Kota Blitar ini, berupa pemberian sanksi administratif atau sanksi pidana pelanggaran. Sanksi administratif diberikan terhadap pimpinan, pengelola, serta penanggungjawab KTR berupa pemberian teguran lisan, teguran tertulis, penghentian sementara kegiatan, penghentian tetap kegiatan, pencabutan sementara izin, pencabutan tetap izin, maupun denda administratif. Sedangkan sanksi pidana bagi setiap orang yang sengaja melanggar KTR, adalah dipidana kurungan paling lama 3 (tiga) bulan atau denda paling banyak Rp 50.000.000,- (lima puluh juta rupiah).

Perda KTR Kota Blitar dalam bingkai kebijakan pengendalian rokok di wilayah yang berindustri tembakau, mesti dipahami dengan memperhatikan prinsip-prinsip Etika, menimbang tujuan hukum yang bukan hanya berorientasi pada kepastian hukum, tetapi juga kemanfaatan dan keadilan. Prinsip-prinsip Etika yang dapat diterapkan dalam membingkai kebijakan pengendalian rokok, yaitu 1. Prinsip kebaikan, dimana Perda KTR Kota Blitar sebagai salah satu wujud kebijakan pengendalian tembakau bertujuan mengurangi kesakitan dan kematian yang berkaitan dengan tembakau; 2. Prinsip tidak mencelakakan untuk memastikan bahwa resiko dan konsekuensi yang tidak diinginkan dapat diminimalkan ketika mengembangkan program dan kebijakan KTR; 3. Prinsip keadilan, menimbang efek konsumsi tembakau tidak sama dirasakan oleh semua penduduk (warga) Kota Blitar. Ada kesenjangan dalam konsumsi tembakau yang signifikan dan perlu diperhatikan. Para perokok yang menjadi korban adiksi nikotin rokok perlu dilindungi dari ketidaktahuan akan dampak negatif konsumsi rokok dengan kebijakan yang melindunginya, dan warga Kota Blitar yang bukan perokok, wajib mendapat perlindungan dari segala aktifitas merokok; 4. Prinsip transparansi, dimana kebijakan KTR harus bersifat transparansi dalam menjelaskan hubungan di dalam kerangka kerja yang tepat dan mengungkapkan hubungan yang adil dengan semua mitra kolaboratif; 5. Prinsip kebenaran, dimana kebenaran tentang bahaya tembakau yang telah nyata dan terbukti secara ilmiah harus diungkapkan; 6. Prinsip menghormati otonomi., dalam arti prinsip otonomi dalam kebijakan KTR dalam kerangka pengendalian tembakau menghormati otonomi semua individu, baik perokok maupun bukan perokok. Untuk perokok kebijakan ditujukan untuk mengatur tempat yang diperbolehkan untuk 
merokok. Sebaliknya, hak bukan perokok untuk tidak terpapar asap rokok juga harus dilindungi. ${ }^{22}$

Perlindungan hukum terhadap aktifitas merokok di Kota Blitar yang menerapkan prinsip menghormati otonomi antara lain dengan adanya kebijakan smoking area di tempat kerja. Hal ini sangat berbeda dengan penerapan kebijakan KTR di kota negara lain seperti Kota New York, dimana tempat kerja merupakan bagian dari kawasan 100\% bebas asap rokok. ${ }^{23}$ Negara lain seperti Irlandia, Selandia Baru, Uruguay, dan Inggris juga menerapkan kebijakan KTR bebas asap rokok 100 \% di tempat kerja. ${ }^{24}$ Perbedaan proses regulasi kawasan bebas asap rokok, dapat dipahami menimbang regulasi ini harus diterapkan secara bertahap, tidak bisa secara serta merta, menimbang adanya banyak faktor terkait yang bertentangan, tidak saja soal faktor kesadaran hukum, namun juga faktor ekonomi bisnis, kesehatan, juga faktor budaya. Kendati penerapan regulasi KTR secara bertahap, namun harus menuju pada pelaksanaan regulasi kawasan bebas asap rokok, menimbang semua orang berhak dilindungi dari paparan asap rokok orang lain.

\section{PENUTUP}

Perlindungan terhadap warga negara Indonesia di tingkat daerah Kota Blitar terhadap aktifitas merokok di Kota Blitar terepresentasi pada Peraturan Daerah Kota Blitar Nomor 1 Tahun 2019 tentang Kawasan tanpa Rokok (Perda KTR Kota Blitar). Di tempat kerja, orang hanya dapat merokok di smoking area. Namun di kawasan fasilitas pelayanan kesehatan, tempat proses belajar mengajar, tempat anak bermain, tempat ibadah dan angkutan umum, orang sama sekali tidak dapat melakukan aktifitas merokok. Bagi pihak terkait yang tidak melaksanakan kewajiban berdasarkan Perda KTR Kota Blitar, akan dikenai sanksi administratif, dan sanksi pidana bagi pelaku tindak pidana pelanggaran Perda KTR Kota Blitar.

Kebijakan kawasan tanpa rokok bukan tentang apakah orang merokok tetapi dimana orang merokok. Hal ini masih meninggalkan konsekuensi resiko kesehatan bagi orang lain yang menghisap asap rokok, sehingga hanya dengan penerapan KTR 100\% yang dapat melindungi orang dari paparan asap rokok orang lain.

22 Baca Op.Cit., Jurnal Kebijakan Kesehatan Indonesia, Vol. 01, No. 2 Juni 2012, h.117.

23 TCSC IAKMI, Fact Sheet, Landasn Hukum bagi Kawasan Tanpa Rokok, Jakarta: TCSC-IAKMI.

24 Ibid. 


\section{DAFTAR PUSTAKA}

\section{Buku:}

Intan Suryantisa, Situasi Umum Konsumsi Tembakau di Indonesia, Jakarta: Kementerian Kesehatan RI, 2018.

Johnny Ibrahim, Teori dan Metode Penelitian Hukum Normatif. Cet. 4, Malang: Bayumedia Publishing, 2011.

Kota Blitar dalam Angka 2020, Blitar: BPS Kota Blitar.

Phillipus M. Hadjon, Perlindungan Hukum bagi Rakyat Indonesia, Surabaya: PT. Bina Ilmu, 1987.

Prof. Dr. Suteki, S.H.,M.Hum., dan Galang Taufani, S.H.,M.H Metodologi Penelitian Hukum (Filsafat, Teori dan Praktik). Depok: Rajawali Pers, 2018.

TCSC IAKMI, Fact Sheet, Landasn Hukum bagi Kawasan Tanpa Rokok, Jakarta: TCSCIAKMI.

\section{Jurnal:}

Nizwardi Azkha, "Studi Efektivitas Penerapan Kebijakan Perda Kota Tentang Kawasan Tanpa Rokok (KTR) dalam Upaya Menurunkan Perokok Aktif di Sumatera Barat Tahun 2013", Jurnal Kebijakan Kesehatan Indonesia, Vol. 02, No. 4 Desember 2013.

Ekowati Rahajeng, "Pengaruh Penerapan Kawasan Tanpa Rokok Terhadap Penurunan Proporsi Perokok di Provinsi DKI Jakarta, Daerah Istimewa Yogyakarta dan Bali", Jurnal Ekologi Kesehatan Vol. 14 No 3, September 2015.

Juanita, "Kebijakan Kawasan Tanpa Rokok: Peluang dan Hambatan", Jurnal Kebijakan Kesehatan Indonesia, Vol. 01, No. 2 Juni 2012.

Kwe Fei Lie Shirley, Endang Wahyati Y. dan Tammy Juwono Siarif. Kebijakan tentang Pedoman Kawasan Tanpa Rokok Dikaitkan dengan Asas Manfaat. SOEPRA Jurnal Hukum Kesehatan, Vol. 2 No. 1 Th. 2016.

\section{Peraturan Perundang-undangan:}

Undang-Undang Republik Indonesia Nomor 36 Tahun 2009 tentang Kesehatan Peraturan Daerah Kota Blitar Nomor 1 Tahun 2019 tentang Kawasan Tanpa Rokok

\section{Internet:}

International Agency Research on Cancer (IARC) Monograph Evaluation of Carcinogenic Risks to Humans, Tobacco Smoke and Involuntary Smoking July 2002 , http://monograph.iarc.fr/htdocs/indexe s/vol83index.html

Chan-Yeung and Ward. Respiratory health effects of exposure to environtmental tobacco smoke.

http://www.cdc.gov/tobacco/global/gyts/GYTS_factsheets.htm https://databoks.katadata.co.id/datapublish/2019/05/31/indonesia-negara-denganjumlah-perokok-terbanyak-di-asean, diakses pada Juli 2020. 